\title{
Adjektiivide tajumine ja õpetamine
}

\author{
HEINIKE HEINSOO \\ Tartu Ülikool
}

Ülevaade. Artiklis uuritakse, kuidas eestlased kasutavad adjektiive soome keeles ja milliseid probleeme tekitavad sünonüümid ja kollokatiivsed sõnapaarid. Artikli teises pooles analüüsitakse üliõpilastega (A2.2-B1.1) läbiviidud adjektiivide kasutamise teste. Testid käsitlevad nii põhisõnale adjektiivi kui ka adjektiivile sobiva põhisõna leidmist. Erilist tähelepanu pööratakse sõnaraamatu kasutamisel esile kerkivatele raskustele, nende teadvustamisele ja lahendamise võimalustele. Täieliku sünonüümia puudumine ja lekseemi erinevate tähendusvarjundite tajumise raskus põhjustavad sõnakasutusel suuri probleeme. Sõnade esmatähendus on enamasti sarnane, aga sekundaarne kasutus võib eesti ja soome keeles tunduvalt erineda. Soovitav on õppida sõnapaare kollokatiivselt.

Võtmesõnad: sünonüümia; kollokatiivsus; võõrkeeleõpe; soome keel

\section{Adjektiiv annab värvi}

Adjektiivid rikastavad meie keelt ja on sageli meie suhtumise väljendamiseks vältimatud. Näiteks ilmast rääkides ei saa me öelda: väljas on ilm, sm ulkona on sää/ilma. Antud substantiiv nõuab obligatoorse laiendina adjektiivi: väljas on külm, soe, hea ilm, sm ulkona on kylmä, lämmin, hyvä sää. Soome sõnal ilma on kaks tähendust: 'ilm' ja 'õhk', aga adjektiiviga hyvä assotseerub soomlastel ennekõike tähendus 'ilm'. Adjektiivi põhifunktsioon on esineda atribuudina: kongrueeruv atribuut $68,8 \%$, substantiivne kasutus 6,3\%, predikatiiv 7,6\%. (Hakulinen, Karlsson 
1988: 77). Adjektiivide osast üldsõnavaras ütleb soome sagedussõnaraamat järgmist:

Adjektiivit eivät muodosta merkittävää ryhmää kärkipään sanojen joukossa. Niitä on tässä vertailuryhmässä 8 (pelkkiä adjektiiveja 7) ja niiden frekvenssi on $1,4 \%$ kaikkien aineiston sanojen frekvenssistä. Ensimmäinen adjektiivi on suuri (22.). Adjektiiveista viidentenä on vastakohtana pieni: Nämä yhdessä ilmaisevat kokoa, joka siis näyttää olevan tärkein adjektiivien käsite. Oma on ilmeisen tärkeä suomalaiselle, koska se on uuden kanssa toiseksi yleisin adjektiivi. Positiiviset adjektiivit, kuten neljäntenä oleva hyvä näyttävät olevan suositumpia. Uusi on niin ikään yleisempi kuin vanha. (Saukkonen jt 1979: 10.)

Et mõista loetava teksti üldist tähendust, peab aru saama vähemalt 70-75\% sõnadest. Põhisisu mõistmiseks tuleb aru saada 90\% ning detailide ja nüansside tajumiseks koguni 95\% sõnadest (Kristiansen 1996: 96). Adjektiivid kuuluvad kindlasti just nüansse lisava sõnavara hulka. Mitmed Soomes läbiviidud uurimused näitavad, et sõnavara õpetuses puudub süstemaatilisus ning piirdutakse üksiksõnade õpetamisega (Aalto 1994: 93). Adjektiive ei saa aga mingil juhul õpetada ilma põhisõna sisu teadmata. Adjektiivi tähendusest võib keeleõppija aru saada, aga iseseisev sobiva sõnapaari leidmine on raske. Näiteks on üsna selge, et ohut ilma tähendab eesti keeles hõre õhk, aga sama väljendit ise moodustades valitakse sõnapaari kollokatiivsust tundmata ilmselt mõni muu soome keele adjektiiv.

\section{Sõnaraamat adjektiivide õppimise abivahendina}

Olen küsitlenud, milliseid probleeme tekitab sõnaraamatu kasutamine. Tavalisimaks on sünonüümide rohkus. Sõnale puhas saame soome keeles kaks vastet: puhdas, siisti. Pöörates otsingu teistpidi ja vaadates, milliseid tähendusi ja tähendusvarjundeid sõna(de)l on, saame järgmised tulemused. 
puhdas: 1. puhtaks pestud, kasitud; 2. (siveellisesti moitteeton), puhas, laitmatu, vooruslik, veatu; õilis; 3. (virhhetön) puhas, veatu, laitmatu; 4. (sekoittamaton) puhas, ehtne: 5. (pelkkä) puhas; (nettomääräinen) puhas.

siisti: 1. (ulkoasultaan puhdas) korras, hästi korrashoitud; (kunnollinen, järjestyksessä oleva) korralik, viisakas; (tahraton) plekitu, puhas, määrimata, (puhtautta suosiva) puhtuse armastaja, puhtust armastav. 3. korralik, kombekas, viisakas, korrektne. 4. (hieno, kaunis) ilus, peen; (hyvä (ark.)) vahva, tore, maru, äge, kihvt.

Ka adjektiiv värske on paljutähenduslik. Ajaleht, õhk, puuvili, uudis, toit, õhk on värske. Soome keeles kasutatakse sõna tuore ühendites tuore sanomalehti, hedelmä, uutinen, sanomalehti, aga raikas/raitis sõnaga ilma, kusjuures raitis on tähenduses 'värske', raikas tähenduses 'värske, karge' (seega lisavarjundiga 'külm'). Samas on raikas sõna tähenduste hulk üsna suur.

\section{Sünonüümia}

Adjektiive õpetame tavaliselt seoses teatud teemadega. Õppimine algab enda ja oma pere tutvustamisega. Sealt tulevad isikuomadusi iseloomustavad lihtsad sõnad. Järgnevad teemad kodust, ostmisest, söömisest, reisimisest, haigustest jne. Omadussõnad tulevad omaette sõnaliigina esile kompareerimise õpetamisel (Heinsoo 1991: 52 jj). Iga teema annab uusi omadussõnu ja sageli ka kollokatiivseid väljendeid. Igal adjektiivil on sünonüüme - täpsemaid ja vähem täpsemaid ja sünonüümidest võib moodustada jadasid, kus üha enam hakkab domineerima mingi muu tähendus. Terminit sünonüüm kasutatakse üldiselt viitamaks sellistele vormilt erinevatele sõnadele, mille denotatiivne tähendus on identne. Sünonüümia kahe lekseemi vahel on täielik, kui sünonüüme võib vastastikku teineteisega asendada igas kontekstis, ilma et muutuks denotatsioon ja väljendi tõeväärtus, stiil või afektiivne tähendus (Karlsson 1998: 219). Täielikke sünonüüme on keeles väga vähe või üldse mitte. 
Olen käsitlenud soome ja eesti adjektiive mentaliteedivõrdluse seisukohalt (Heinsoo 2003, 2002, 1999). Uurimustes tuleb selgelt välja nn sünonüümipesade tähendusnihe. Cruse mainib, et sünonüümide tähendused on pealistikused, st neil on omavahel nii ühiseid kui ka eristavaid omadusi. Tähenduse samasus avaldub sünonüümidel sel moel, et nad on identsed kesksemate semantiliste omaduste poolest, aga võivad erineda perifeersete joonte puhul. (Cruse 1986: 267) Konnotatiivsed kõrvaltähendused eristavad sõnu, annavad neile nüansi või hinnangu. Sünonüümipesas, mis väljendab nt kena välimust, on adjektiivide sievä, nätti, kaunis, upea, komea tähenduse vahel erinevusi, seda enam, et naissoo esindaja puhul kasutatakse adjektiivina upea (nainen) ja meessoos esindaja puhul komea (mies). Siiski, president Halose kohta öeldakse komea nainen. Eesti keeles on sõna kaunis tarvitusel naissooesindaja iseloomustamiseks.

Ka täissünonüümsetel sõnadel võib olla oma kasutusala. Nt sõnad suuri ja iso on absoluutsed sünonüümid, aga liitsõnades on kasutus kollokatiivne: isovanhemmat 'vanavanemad', isosisko 'vanem õde'; suurkaupunki 'suurlinn'. Suuri mies on kogukas, pikakasvuline mees, suurmies 'suurmees', isokenkäinen 'suur asjamees, lai leht'. Kuna eesti keeles esineb vaid sõna suur, arvab eesti õppija, et suuri ja iso sõnade vahel peab olema oluline erinevus.

Sünonüümia on üks paradigmaatilise tähendussuhte vormidest. Enamasti see tähendab kahe või enama vormilt erineva lekseemi samatähenduslikkust (Jantunen 2004: 53). Täielikku samatähenduslikkust praktiliselt pole. Näiteks kui otsida soomekeelset vastet sõnale halb, siis tekivad probleemid. Kas paha ja huono sõnal on vahe? Kui otsida soomekeelsest netisõnaraamatust "Suomenkielisia synonyymisanoja" (http: synonyymi.net/index) sünonüüme sõnale halb, saame tulemuseks üsna aukartustäratava valiku.

huono: apea, heikko, huolimaton, ikävä, kehno, kelvoton, kovin kulunut, kyvytön, niukka, onneton, puutteellinen, raihinas, ruma, ränsistynyt, sairas, sopimaton, surkea, taitamaton, vaikea, vajavainen, viallinen, voimaton, vähäinen, epäedullinen, haitallinen, huono, ikävä, vaaral- 
linen, vahingollinen, hankala, kiperä, pulmallinen, raskas, rasittava, tukala, työläs, vaativa, vaivalloinen, visainen.

paha: huono, kelvoton, lainvastainen, laiton, moraaliton, rikollinen, sopimaton, syntinen, säädytön, häijy, julma, karkea, pahanilkinen, pahansuopa, pahantapainen, raaka, törkeä.

Üldistavate ja heal keeleoskusel põhinevate mõtiskluste tulemusel võiks öelda, et paha liitub inimliku substantiivdenotaadiga ja annab tegudele moraalse hinnangu.

Sünonüümisuhtes olevate sõnade tähendused võivad erineda üksteisest väga erinevates dimensioonides. Võõrkeele õpetamisel on suhtumine sünonüümiasse sageli vastuoluline. Teisalt tunnustatakse sünonüümia nüansirohke valdamise tähendust, teisalt seda lihtsustatakse ja õppijale antakse norme (Vanhatalo 2005: 21). Normidena võiks käsitleda ka adjektiivide õpetamist kollokatiivsete ühenditena.

\section{Kollokatiivsed paarid}

Kollokatsioonide all mõeldakse sõna tähendusest lähtuvaid tendentse esineda koos teatud sõnadega. Kollokatsioonide väljaselgitamine eeldab üldiselt suurte tekstikorpuste kasutamist. Tundubki, et hea oleks kõik adjektiivid ära õppida mingil määral kollokatiivsete paaridena, vähemalt juhul, kui sõnal võib olla püsiühendeid, nt uusi kuu, eesti keeles noor kuu; uudet perunat eesti keeles värsked kartulid.

Kollokatsioonidest on kirjutanud Tartu Ülikoolis BA-töö Kadri Jaanits ja Made Riet (Jaanits, Riet 2000). 2001. aastal valmis Kadri Jaanitsa ja Maarja Keba õpetajakoolituse lõputöö soome väljendite õpetamisest (Jaanits, Keba 2001). Eesti ja soome kollokatiivsetest väljenditest kirjutas magistritöö Kadri Jaanits (Jaanits 2004). See sisaldas ka kollokatsioonisõnastikku. Kollokatsiooni põhisõnaks on autoril noomen ja kollokeerujaks verb või adjektiiv, nt uni + sügav = sügav uni, aga sm sikeä uni. Näide Jaanitsa kollokatsioone käsitlevast magistritööst: 
ILMA ÕHK, ILM

$\mathbf{V}^{\mathbf{1}}$ : lämpenee ilm/õhk soojeneb, on raskasta õhk on (millestki) raske, $\sim$ viilenee ilm/õhk jaheneb $\mathbf{V}^{2}$ : haukata raitista ilmaa värsket õhku hingata, heittää ilmaan õhku visata, nousta ilmaan õhku tõusta

A: huono halb ilm, hyvä hea ilm, kaunis ilus ilm, ohut hõre õhk, raikas/raitis värske õhk, ruma kole ilm, tunkkainen umbne õhk

Hea näide sellest, kuidas sõna ilma tähendus muutub koos täiendiga: tunkkainen, raikas, raitis, ohut ilma 'raske, karge, värske, hõre õhk', huono, ruma, hyvä, kaunis ilma 'halb, hea, ilus ilm'. Ehkki ka õhk-sõna puhul võiks kasutada adjektiive hyvä ja huono, seostub esimene kujutluspilt siiski ilmaga. On olemas stereotüüpsed kollokatsioonid, nt viisakusväljendid: Hyvää uutta vuotta! Head uut aastat! Rauhallista joulua! Rahulikke jõule!

Soome Instituut andis välja harjutusvihiku väljendite õpetamiseks teemade kaupa (Jaanits, Keba 2004).

Mõned sõnad on teistest populaarsemad. Need kas esinevad teatud kontekstis sagedamini või on siis õpetatud keeleõppijale esimeses järjekorras.

Katseks võtsin Internetist lihtsa teksti, kuhu pidi lisama adjektiive (pakutud adjektiivid on kursiivis).

Adjektiivit tekevät kertomuksesta värikkään (http: //www.merikartano.fi/ tuomo/suomi/peikko.php)

Pöllö ja Peikko

Pöllö ja Peikko ovat hyvät ystävät. He asuvat pimeässä, paksussa, kauniissa, tummassa, isossa, vanhassa metsässä. Metsä on kaukana pienistä, isoista, kylistä ja isoista, suurista kaupungeista. Siellä on harvoin ilkeitä ihmisiä. Pöllöt ja peikot ovat erilaisia. Peikko ei ole suuri, tavallinen eläin. Pöllö on viisas, kaunis lintu. Linnut ovat eläimiä. Pöllö on yöeläin. Kun laiska, aamutorkku Pöllö vasta herää, on ahkera, aamuvirkku Peikko jo ehtinyt puuhailla kaikenlaista. 
Pöllön uusi asunto on paksun, korkean, pitkän kuusen latvassa. Lehdettömän, vanhan puun kyljessä on salainen kohta. Jos katsot tarkasti, huomaat, että se on pieni ovi. Pöllön ahdas asunto on mukava. Siinä on vain yksi ahdas, pieni, viihtyisä, iso huone. Huoneessa on pieni, puinen punainen tuoli, matala, vihreä pöytä ja kapea, pehmeä, mukava sänky.

Peikko asuu saman paksun, vanhan kuusen alakerrassa. Eräs ison, kuolleen puun juuri on hieman koholla maan pinnasta. Sen alta pilkotti pimeän luolan suu. Jos möngit siitä sisään, tulet Peikon matalaan, mukavaan majaan. Se on viihtyisä, vaikka siellä tuoksuu vähän turve. Peikon suuressa huoneessa on vain pehmeästä, vihreästä sammaleesta tehty vuode ja vanha, isokeltainen öljylamppu. Peikko oli löytänyt kirkkaan, vanhanaikaisen lampun kauan sitten. Joku oli tiputtanut sen metsän laitaan.

Paarkümmend kirjutajat kasutasid üsna samasuguseid adjektiive. Esinesid sünonüümid või siis antonüümid (suuri - pieni), hinnangud (kaunis), värvid, aga ka üsna palju enam-vähem kollokatiivseid seoseid: hyvä ystävä, suuri vanha metsä, suuri (iso) kaupunki, viisas pöllö, korkea, vanha kuusi, pimeä luola, pehmeä sänky. Kindlasti moodustavad kollokatiivse paari hyvä ystävä, sest seda sõbralt oodatakse, ja viisas pöllö, kuna öökulli üldtuntud omaduseks on tarkus.

Kollokatsioonid on transparentsed emakeele kõneleja jaoks. Emakeelt kõneldes ei märkagi me tavaliselt, milliseid sõnu ja kuidas me omavahel ühendame. Olukord muutub märgatavalt võõrkeelt õppides või rääkides. Vahel paistab mõni sõnaühend metafoorilise või veidrana. Tundub, et sõnaraamatus antud tähendusel pole midagi ühist selle tähendusega, mille sõna mingis väljendis võib saada. Soomekeelne sõnasõnaline tõlge eesti väljendile kõht on lahti (sm vatsa on auki) on veider, õige tõlge on vatsa on löysä 'kõht on vedel'. Sama võime öelda väljendi ohut ilma kohta, mis ei ole eesti keeles mitte õhuke vaid hõre õhk, samas on aga väljend ohut tukka ka eesti keeles hõredad juuksed.

Adjektiivid pole sugugi vabalt kollokeeruvad. Vähemalt piiratud kollokatsioonis võib adjektiiv moodustada põhisõnaga vägagi püsiva üksuse. Näiteks: värske kartul, sm uusi peruna, must kohv, sm musta 
kahvi. Antud juhul on põhjuseks see, et adjektiividele värske või must (värvus) ei leidu kuigi palju sünonüüme ja et mõlemat adjektiivi kasutatakse piltlikus tähenduses. Sõnapaari blondid juuksed, sm vaalea tukka puhul on kollokatiivne eesti sõnapaar - blondid võivad olla vaid juuksed (mitte nt püksid). Kollokatsioonid on siiski transparentsed selles mõttes, et terviku tähendus on teatud mõttes oma osade tähenduste summa ehk kollokatsiooni tähendust on võimalik mõista tema osade tähenduse kaudu. Emakeele kõneleja ei pruugi nt idioome ilma eelteadmisteta mõista. Kuigi must kohv on oma värvilt pigem tumepruun, on kollokatsiooni tähendus 'kohv ilma koore või piimata' selge ja üheselt mõistetav. (Jaanits 2004: 12)

\section{Soome keele õppijatega läbiviidud testid}

Testisin suhteliselt hästi soome keelt oskavaid üliõpilasi (A2.2-B1.1 tase) ja jälgisin nende sõnavara laiust, võimet leida sünonüüme eri tähendusrühmades, ja adjektiivide valdamist üldse.

\subsection{Leia mõisteväljale soomekeelne adjektiiv!}

Test põhines Heili Orava isiksuseomadusi käsitleval dissertatsioonil (2006: 7-8), kuna üsna palju vaatlusteemasid põhineb isikute kirjeldamisel - kirjeldada tuleb oma pereliikmeid, sõpru, ülemust, naabreid jne. Rühmad olid läbinud põhikursuse Margit Kuuse õpiku "Suomi selväksi" (2005) põhjal. Üliõpilased pidid märkima adjektiivid, mis seostusid neil teatud omadustega (Orava töös esinenud järjekorranumbrid on muudetud). Vastus pidi põhinema esimesel reaktsioonil. Esimene test tehti tunnis (21 üliõpilast erinevatest A2-B1 rühmadest) sõnaraamatuta ja hiljem otsiti vajalikke sõnu juurde kodus ka sõnaraamatust. Eesmärgiks polnud täiusetaotlus vaid enamkasutatava sõnavara leidmine. Kursiivis on vastused ja tegelikult saime rühma peale kokku enamasti vaid ühe sõna. 
Interpersonaalsed isikuomadused:

1. Sõbralikkus ystävällinen, mukava;

2. Suhtlusoskus:

2.1. Jutukus puhelias, 2.2. Õpetamine ikävä, 2.3. Vaidlemisoskus riidanhaluinen, sanaseppä, 2.4. Naljasoon humoristinen

3. Seltskondlikkus hyväntuulinen, seurallinen, puhelias, 4. Avatus reilu, välitön, 5. Ausus (epä)rehellinen, reilu, 6. Usaldusväärsus luotettava, 7. Usaldamine luottavainen, hyväuskoinen, 8. Abivalmidus avulias, 9. Hoolivus reilu, 10. Viisakus kohtelias, huomavainen, 11. Ülbus koppava, ylpeä, 12. Domineerimine ???, 13. Kadedus kateellinen, 14. Truudus uskollinen, 15. Suuremeelsus jalo, 16. Õiglustunne rehellinen, 17. Koostöö ???, 18. Ihnus saita, 19. Ahnus ahnas, ahmatti (subst), 20. Paindlikkus joustava, 21. Seksuaalsus seksikäs

II. Interpersonaalsed isikuomadused

1. Inimese käitumises avalduvad omadused

1. Töökus työteliäs, ahkera, 2. Osavus taitava, 3. Edasipüüdlikkus yritteliäs, toimelias 4. Sihikindlus sisukas, 5. Otsustavus päättäväinen, 6. Julgus rohkea, 7. Praktilisus kätännöllinen, 8. Realistlikkus realistinen, 9. Korralikkus kunnollinen, siisti, 10. Vastutustundlikkus velvollisuudentuntoinen, 11. Kohusetundlikkus velvollisuudentuntoinen, 12. Konservatiivsus vanhollinen, 13. Kiirus nopea, kiireinen, 14. Teotahe toimelias, 15. Temperamentsus vilkas, 16. Tundlikkus herkkä, 17. Rahulolematus tyytymätön, oikukas, 18. Naiselikkus/ mehelikkus naisellinen, macho

2. Intellektuaalsed võimed

1. Intelligentsus älyks, etevä, lahjakas, nerokas, 2. Õppevõime ja -huvi ahkera

Test oli raske ja sisaldas palju tühje kohti. Sõnaraamatu abita jäi palju täitmata, vahel oli raske ka emakeeles sobivat adjektiivi leida.

\subsection{Soomekeelsele adjektiivile põhisõnaleidmine}

Tabel 1 esitab tulemused ülesandele: pane vähemalt kolm põhisõna, mille täiendiks need adjektiivid sobivad. 
TABEL 1. Üliõpilaste poolt etteantud adjektiividele pakutud põhisõnad

\begin{tabular}{|c|c|c|c|c|}
\hline pitkä & matka & tie & ihminen & aika \\
\hline lyhyt & matka & tyttö & jono & aika \\
\hline matala & maja & talo & puu & \\
\hline suuri & kaupunki & maa & puu & päätös \\
\hline iso & kissa & oksa & päätös & haave \\
\hline puhdas & lumi & iho, kasvot & paperi & huone \\
\hline siisti & ihminen & keittiö & huone & juttu \\
\hline komea & tyttö, poika & turkki & talo & näköala \\
\hline lauhkea & ilmasto & hevonen & tuuli & sää \\
\hline leuto & tuuli & talvi & & \\
\hline lempeä & äiti & hymy & & \\
\hline kapea & käytävä & katu & salmi & tie \\
\hline ahdas & hame & aukko & käytävä & \\
\hline helppo & harjoitus & nakki (ideom)! & läksy & kieli \\
\hline vaikea & kieli & harjoitus & kysymys & ratkaisu \\
\hline \multicolumn{5}{|l|}{ kevyt } \\
\hline tiukka & aikataulu & sääntö & käsky & valvonta \\
\hline leveä & tyyli & tie & ikkuna & katu \\
\hline laaja & valikoima & kaista & näkökulma & alue \\
\hline karkea & suola & hiekka & & \\
\hline painava & laukku & sana & kuorma & kassa \\
\hline raskas & työ & kalusto & mieli & \\
\hline tanakka & & mies & ihminen & nainen \\
\hline voimakas & ihminen & koira & käsi & \\
\hline vahva & aate & mielipide & mies & leijona \\
\hline väkevä & & ihminen & tuuli & \\
\hline terävä & veitsi & juoma & mies & \\
\hline mieto & kahvi & alkoholi & & \\
\hline tulinen & pannu & vesi & & \\
\hline tylsä & ihminen & juttu & päivä & veitsi \\
\hline tuore & salaatti & omena & pääjohtaja & \\
\hline raaka & voima & tuuli & omena & \\
\hline ikävä & tapaus & juttu & ihminen & \\
\hline valoisa & huone & päivä & kesä & tyttö \\
\hline kamala & & kylmä & sää & kärsimys \\
\hline kauhea & & kankkunen & mies & nuha \\
\hline hirveä & ihminen & pakkanen & päänsärky & \\
\hline makea & kakku & elämä & hillo & suklaa \\
\hline maukas & ruoka & ${ }^{\star}$ mekko & kakku & liha \\
\hline
\end{tabular}


Kui tabeli 1 esimene lahter on tühi, tähendas see seda, et paljudele õppuritele oli sõna tundmatu.

Sõnavalik oli selline, et eesti keele ühele adjektiivile vastas soome keeles sageli mitu erinevat adjektiivi, nt ahdas, kapea, tiukka 'kitsas, tihe'. Peale testi tegemist arutasime tulemusi koos Soome Instituudi praktikandi Pauliina Perkkiöga ja üliõpilased küsisid palju nüansse, ülekantud tähenduse sarnasust eesti ja soome keeles jne. Emakeelsele soomlasele olid küsimused huvitavad ja test läks ringlema. Sõnaraamatust abi otsimine tõi vigast kasutust sageli juurde, kuna sealt leiti sõnu, mille tähendusvarjund oli võõras. Kuna sõnad on väga paljutähenduslikud, siis sünnib pelgalt sõnaraamatu abi kasutamisel nendega palju kasutusraskusi. Ulla Vanhatalo rõhutab, et sõnaraamatu ühiskondlikku tähtsust on raske piisavalt rõhutada. Sõnaraamatu kõige ohtlikum ja traditsioonilisem (ehkki mitte kõige enam teadvustatud) risk on see, et sõnaraamatut kasutavad inimesed usuvad kergesti, et sõnaraamat esindab lõplikku tõde (Vanhatalo 2005: 44). Igatahes on sõnaraamatu tõde sageli raske välja lugeda. Sõnakasutuse semantikal ja pragmaatikal on omad riskid.

\section{Semantiline analüüs}

Semantilises analüüsis räägitakse tavaliselt kas lähisünonüümidest või kognitiivsetest sünonüümidest. Need võivad teineteisest stilistiliselt erineda, nõutav on siiski tõeväärtuslik ja süntaktiline identsus (Cruse 1989: 270). Lausele vastav tõesus peab jääma samaks mõlema sünonüümi puhul. Sünonüümipesade paljud sõnad ongi sageli stilistiliselt markeeritud, nii et neid saab kasutada ainult teatud kontekstis. Osa lähisünonüümidest võib sobida ainult mingi kindla tekstiliigiga. Eraldavad tunnusjooned võivad olla ka keelevälised valikukriteeriumid, nagu näiteks kommunikatsioonisituatsioon või kõneleja suhtluseesmärgid. (Jaanits 2004: 23)

Adjektiive on üritatud semantiliselt mitmeti jagada. Leppijärvi ja Jämsä jaotuse (1976: 5-10) aluseks on peasõna denotaadi tähendus. Peasõna tähendust iseloomustab kas: 1) füüsilisus - peasõna on väljaspool 
inimtaju või 2) psüühilisus - peasõna kuulub inimtajusse. Jantuneni jaotus põhineb kollokaatide tekstiümbrusest sündival tähendusel. Jantunen tõdeb, et alati pole kollokaatide rühmitamine probleemideta, sest sageli kuulub sõna mitmesse rühma. Tähelepanu on pööratud kollokaadi tähendusele antud kontekstis (Jantunen 2004: 135-136).

\section{Kokkuvõte}

Adjektiivide varieeruvus on pisut suurem kui verbidel, see tähendab eelkõige seda, et leidub rohkem võimalikke sobivaid variante (Jaanits 2004: 27). Kommunikatiivse keelekasutuse esimene eeldus on piisava sõnavara valdamine. Kui õppija soovib võõrkeelseid sõnu kõnes kasutada, ei piisa sõnade lihtsalt "ära õppimisest". Suhtlussituatsioonis kasutamiseks peavad sõnad olema kinnistunud produktiivses sõnavaras ning kasutaja peab teadma, millises kontekstis sõna esineb (Saarso 2000: 43). Aalto eristab retseptiivset ja produktiivset sõnavara. Sõna retseptiivne valdamine (äratundmine; arusaamine) tähendab, et õppija tunneb sõna ära ja saab aru selle tähendusest nii kõnes kui kirjas ning suudab sõna eristada teistest sarnastest sõnadest, ja suudab otsustada, kas sõna on esitatud korrektses vormis. Sõna produktiivsel valdamisel (kasutamine; aktiivne kasutamine) lisandub oskus kasutada sõna nii grammatiliselt kui funktsionaalselt õigesti ja sobivalt nii kõnes kui kirjas ning oskus asetada sõna sobivale kohale tema sünonüümide suhtes. Sõna produktiivne omandamine on 50-100\% raskem kui retseptiivne (Aalto 1994: 97), seetõttu tuleks õppijal kaaluda, kas kõiki sõnu on mõtet lisada oma produktiivsesse leksikoni ning õpetaja ülesandeks oleks õpilast selle otsuse tegemisel aidata. Õppija omandab sõnad paremini kontekstis, kui sellest väljarebituna, kontekst ei tähenda aga alati pikkade tekstitervikute loomist (Saarso 2000: 27). Juba kollokatsioon iseenesest on kontekstiks sõnadele, mida ta sisaldab. Laiema konteksti moodustavad teised sama sõna või teemaga seotud kollokatsioonid. See toobki meid juba järgmise põhimõtteni: kollokatsioone tuleks õpetada teemade kaupa. Adjektiivide kasutuse üheks tavaliseks võtteks on Google’i kasutamine, kus frekventsi 
põhjal tehakse valik. Ülekaalukalt kasutatakse vahva viina, aga viini sõna adjektiivina enam-vähem võrdselt vahva, väkevä. Eesti keeles kange viin, vein, tee, soome keeles vahva tee 'kange tee'.

On selge, et kollokatsioonide tohutu hulga tõttu keeles ei ole võimalik neid kõiki õpetada. Bahns (1993) väidab, et õpetama peaks ainult selliseid kollokatsioone, mis erinevad sõnavalikult õppija emakeeles ja õpitavas võõrkeeles, aga sõnavara süstemaatilisel õpetamisel tuleks ehk pigem (vähemalt algajate õpetamisel) lähtuda kollokatsiooni olulisusest, esinemissagedusest ja käsiteldavast teemast.

Testidest ilmnes, et adjektiividest koosnev sõnavara on selles õppimisfaasis veel üsna primitiivne. Nüansse ei mõisteta ja kardetakse. Adjektiive peaks ilmselt õpetama laiema konteksti kaudu või siis lisama, millised eesti keelest erinevad kasutused sõnal on. Adjektiivide õppimine on lõputu protsess nii nagu keele õppimine üldse. Sõna ei saa lahku lüüa kontekstist, adjektiivi põhisõnast, keelt kasutajast. Selge on see, et sõnade primaarne tähendus ei põhjusta tavaliselt raskusi, nt suur, väike, noor, vana, uus jne. Küll aga on vigade parandamise käigus leidunud selliseid vääraid adjektiivikasutusi nagu ylpeä ravintola 'uhke restoran', herkkä mummo 'hell vanaema' jne. Seega on õpetamise algusjärgus oluline tutvustada adjektiivi põhitähendust ja vajadusel anda kollokatiivsed erikasutused, nt suomi ei ole vaikea 'soome keel ei ole raske' ja matkalaukku on painava 'kohver on raske'.

Ulla Vanhatalo on väitnud, et emakeele kõnelejad valivad sõnad spontaanses kõnes peaaegu automaatselt ja teadvustamatult. Sõnavalikut põhjendab ta sellega, et osa sõnavarast on oma iseloomult tugevam: mõned sõnad veavad teisi kaasa (Vanhatalo 2005: 22). Võõrkeele kasutusel on spontaansuseni jõudmine võimatu. Toimub pidev teksti mõtestatud produtseerimine, mis on seda kergem, mida rohkem meie teadmistes on idiomaatilisi ja kollokatiivseid seoseid. 


\section{Kirjandus}

Aalto, Eija 1994. Alussa on sana - systemaattisuutta sanaston opettamiseen. Minna Suni, Eija Aalto (Toim.). Suuntaa suomenopetukseen - tuntumaa tutkimukseen. Korkeakoulujen kielikeskuksen selosteita 4. Jyväskylä: Jyväskylän Yliopistopainos, 93-117.

Bahns, Jens 1993. Lexical collocations: a contrastive view. - English Language Teaching Journal 47 (1), 56-63. doi:10.1093/elt/47.1.56

Dixon, R. M. W. 1977. Where have all the adjectives gone? - Studies in Language 1 (1), 19-80.

Cruse, D. A. 1986. Lexical Semantics. Cambridge Textbooks in Linguistics. Cambridge: Cambridge University Press.

Hakulinen, Auli, Fred Karlsson 1988. Nykysuomen lauseoppia. 2. painos. Suomalaisen Kirjallisuuden Seuran toimituksia 350. Helsinki: Suomalaisen Kirjallisuuden Seura.

Heinsoo, Heinike 1991. Suomea oppimaan. Tallinn: Rahkoi.

Heinsoo, Heinike 1999. Talkative as Finn or an Estonian? - Ago Künnap (Ed.). Indo-European-Uralic-Siberian Linguistic and Cultural Contacts. FennoUgristica 22. Tartu: Tartu Ülikooli Kirjastus, 77-84.

Heinsoo, Heinike 2002. Aus ei ole valelik ja lihtsameelne ei ole kaval. - Piret Klesment (Toim.). Keelekontaktidest keelevahetuseni. Fenno-Ugristica 24. Tartu: Tartu Ülikooli Kirjastus, 88-95.

Heinsoo, Heinike 2003. O aina työn touhussa ku kusiainen. - Pirkko MuikkuWerner, Hannu Remes (Toim.). VIRSU. Viro ja suomi: kohdekielet kontrastissa. Lähivertailuja 13. Joensuu: Joensuun yliopisto, 177-184.

Jaanits, Kadri 2004. Leksikaalsetest kollokatsioonidest soome ja eesti keeles. Magistritöö. Filosoofiateaduskond. Läänemeresoome keelte õppetool. Tartu Ülikool.

Jaanits, Kadri, Made Riet 2000. Leksikaaliset kollokaatiot: määritelmästä ja asemasta kielessä. BA-työ. Tarton Yliopisto. Itämerensuomalaisten kielten laitos. Tarto.

Jaanits, Kadri, Maarja Keba 2004. Harjutusi ja teemasid väljendite õpetamiseks soome keele tunnis. Soome Instituut.

Jantunen, Jarmo H. 2004. Synonyymia ja käännössuomi. Korpusnäkökulma samamerkityksisyyden kontekstuaalisuuteen ja käännöskielen leksikaalisiin ertyispiirteisiin. Joensuun yliopiston humanistisia julkaisuja 35. Joensuu: Joensuun yliopisto.

Karlsson, Fred 2002. Üldkeeleteadus. Tallinn: Eesti keele Sihtasutus. 
Kristiansen, Irene 1996. Tehokkaita oppimisstrategioita kognitiivisen psykologian tutkimustuloksiin pohjautuen. - Marjut Vehkanen (Toim.). Suomi toisena/vieraana kielenä: ajatuksia kielestä, kulttuurista, metodista. Helsinki: OY Edita Ab, 93-122.

Kuusk, Margit 1999. Suomi selväksi. Soome keele õpik. 6., parandatud trükk 2008. Tallinn: Eesti Keele Sihtasutus.

Orav, Heili 2006. Isiksuseomaduste sõnavara semantika eesti keeles. Dissertationes linguisticae Universitatis Tartuensis 6. Tartu: Tartu Ülikooli Kirjastus.

Saarso, Kristi 2000. Sõnavara õpetamine. Keeleõpetaja metoodikavihik. Tallinn: TEA Kirjastus.

Saukkonen, Pauli, Marjatta Haipus, Antero Niemikorpi, Helena Sulkala 1979. Suomen kielen taajuussanasto. Porvoo: WSOY.

Vanhatalo, Ulla 2005. Kyselytestit synonymian selvittämisessä. Sanastotietoutta kielenpuhujilta sähköiseen sanakirjaan. Väitöskirja. Helsinki: Yliopistopaino.

\author{
Heinike Heinsoo \\ Tartu Ülikooli soome-ugri osakond \\ Ülikooli 18 \\ 51014 Tartu, Estonia \\ heinike.heinsoo@ut.ee
}




\title{
Understanding and teaching adjectives
}

\author{
HEINIKE HEINSOO \\ University of Tartu
}

Adjectives make our language richer and often they are necessary in order to express our views. For instance, when discussing the weather, we cannot say: ${ }^{\star}$ there is a weather outside, ${ }^{\star}$ ulkona on sää/ilma. The given noun needs an adjective as an obligatory component: there is cold, warm, good weather outside, Finnish ulkona on kylmä, lämmin, hyvä sää. The Finnish word ilma has two meanings: 'weather' and 'air', while with the adjective hyvä the associated meaning for Finns is above all 'weather'.

The article analyses how the Estonians use adjectives in the Finnish language and what kind of problems the synonyms and collocative word-pairs cause. The second half of the article analyses tests of the use of adjectives carried out with students (A2.2-B1.1). The tests deal with how to find an adjective for a base word and also how to find a fitting base word for and adjective. Special attention will be given for the problems arising when using a dictionary and the realisation of how to resolve those. Because of the lack of a complete synonymic and because of the difficulty of comprehending the different hidden meanings, the usage of words will face great problems. The first meaning of words is mostly similar, but the secondary use can be quite different in Estonian and Finnish languages. It is recommended that the word-pairs are learnt collocatively.

Keywords: synonymy; collocation; foreign language learning; Finnish 